\title{
Health Technology Assessment for Policy Making in India: Current Scenario and Way Forward
}

\author{
Shankar Prinja $^{1}$ - Laura E. Downey ${ }^{2}$ Vijay K. Gauba ${ }^{3}$ - Soumya Swaminathan ${ }^{3,4}$
}

Published online: 13 June 2017

(c) The Author(s) 2017. This article is an open access publication

The Indian government has made a commitment to achieve Universal Health Coverage (UHC) [1, 2], as a means to reduce catastrophic out-of-pocket health expenditure and ensure affordable access to essential health care for the entire population. As part of the plan to deliver UHC, the government has identified ensuring value for money in the health budget to be a key priority $[1,2]$. The central government has outlined a plan to devolve a greater share of the overall tax base to states, who in turn will become more important players in financing health care programmes $[6,7]$. This implies that states will be making resource allocation decisions on what to provide, to whom, and how much. Simultaneously, the central government is increasingly adopting the role of strategic purchaser of health care [3-5].

These ongoing developments require a systematic process for generating policy-relevant evidence that can inform policy decisions regarding health resource allocation, i.e. clinical effectiveness studies, cost-effectiveness studies, budget impact studies, as well as ethical, social and political feasibility studies. This systematic and comprehensive process falls under the broad umbrella of health technology assessment (HTA) [8]. HTA is the international

Shankar Prinja

shankarprinja@gmail.com

1 School of Public Health, Post Graduate Institute of Medical Education and Research, Chandigarh, India

2 Global Health and Development, Imperial College London, St Mary's Campus, London W2 1NY, UK

3 Department of Health Research (DHR), Ministry of Health and Family Welfare, New Delhi, India

4 Indian Council of Medical Research (ICMR), New Delhi, India gold standard for utilizing health economic principles to comparatively assess evidence for cost, clinical effectiveness, safety, and equity to provide evidence as to whether an intervention is a cost-effective investment within a given health system and to assist in the prioritization of health resources. The Government of India's Department of Health Research (DHR), part of the Ministry of Health and Family Welfare (MoHFW), is currently in the process of establishing a medical technology assessment board (MTAB), which will be the central agency for undertaking HTA in India [9].

The MTAB will operate through a three-tier structure, with the secretariat at its base, a technical appraisal committee (TAC) in the middle, and the MTAB at its apex. The name of the recommendatory body is based on its apex tier. The central coordination of activities and development of the HTA processes and methods will be managed by the MTAB secretariat based within the DHR. The TAC will be made up of technical experts drawn from a range of institutes around the country with expertise in a variety of relevant disciplines. The TAC will have the role of prioritizing the topics for which to conduct HTA, quality assuring the analyses produced as part of the HTA, and engaging with and incorporating the views of the various stakeholders relevant to the HTA. A number of technical partners (TPs) will be engaged to conduct the various analyses underpinning the HTAs. The TPs are institutions that have been identified by the DHR as having the capacity to undertake the relevant analyses. The final analyses will be submitted, once quality assured by the TAC, to the MTAB to deliberate on and make recommendations to the Minister of Health and Family Welfare. The MTAB will comprise a wide range of multi-representative members from public, private, academic, and civil society groups. 
The MTAB is expected to operate as a standing recommendatory body with no legislative authority in the first instance. It will develop systems and mechanisms to assess new and existing health interventions, programmes, and technologies in a transparent and inclusive manner [10]. User departments both at the national level, such as the National Health Mission, and agencies managing the funds for various publicly financed insurance schemes, such as Rashtriya Swasthya Bima Yojana (RSBY), as well as state level health departments will provide candidate topics to be evaluated by the MTAB. The MTAB secretariat will investigate these topics and send summaries of each to the TAC, who will prioritize these topics for HTA following a clear and transparent process employing a published set of criteria. The secretariat will then allocate topics that are considered to be of high priority to the TPs who will conduct the analyses underpinning the HTA with the support and oversight of the secretariat. The analyses will be submitted to the TAC, who will quality assure them, and engage with and incorporate the views of all the key stakeholders before producing summaries to be put before the MTAB. The MTAB will discuss each submission, employing a deliberative process to arrive at a recommendation. This recommendation will be submitted to the Minister of Health and Family Welfare for final approval and dissemination into the health system.

The DHR is being supported in this endeavour by leading national technical and academic institutes. The International Decision Support Initiative (iDSI), a collaboration led by priority-setting institutions from the UK's Imperial College London and Thailand's Health Intervention Technology Assessment Program (HITAP), are also providing advice and support to MTAB based on their experiences of establishing HTA processes in other countries.

Establishing HTA in India brings with it several challenges that need to be recognized and addressed. The first and foremost is the existing human resource capacity for undertaking the analyses underpinning HTA. As a recent systematic review on the economic evaluations for health care in India indicates, there is a gross deficiency in the capacity to undertake such studies [11]. While there is significant capacity in undertaking clinical evidence synthesis, there is a dearth of specialist health economists who can undertake assessment of cost-effectiveness for HTA. In order to bridge this challenge, the MTAB has outlined a series of training programmes in the country, in collaboration with national and international partners, to build capacity in the field of economic evaluation. This is supplemented with development of online courses for developing capacity in economic evaluation for HTA [12].

A second challenge is to ensure technical rigour and methodological and process consistency across all TPs undertaking analyses under the MTAB. In order to standardize procedures for topic selection, allocation of topics to TPs, analyses by TPs, appraisal of evidence by the TAC, and consideration of various technical, social, ethical, and political factors by the MTAB when making recommendations, the MTAB secretariat is currently overseeing the development of a process manual, reference case, and detailed methods manual to standardize the processes and analyses underpinning the HTA. These will guide the analyses undertaken by the different TP institutions as well as the decision-making process by the MTAB and ensure the recommendations made by the MTAB are consistent and made in a transparent manner.

A third challenge relates to data availability and quality. Key gaps in the existing data infrastructure in India crucial for conducting HTA are data on the costs of delivering health care services and the lack of a quality-of-life tariff for the Indian population. Research is currently underway to collate evidence from published as well as unpublished studies to develop a national costing database for India [13, 14]. A study is simultaneously being conducted in partnership with the EuroQOL consortium to develop an Indian quality-oflife tariff in order to enable analysts to estimate qualityadjusted life years (QALYs) in the Indian population. This study will utilize the internationally recognized EQ-5D-5L instrument to assess the health-related quality of life associated with various illnesses as judged by a representative sample of the general population in India.

A fourth challenge relates to the ethics and transparency of such a system, particularly in relation to conflicts of interest. This challenge is not unique to the Indian context. To guard against this, the DHR and MTAB will have to ensure the governance of evidence generation in India and safeguard it from vested interests. Established measures to tackle such challenges include using written conflict of interest policies, publication of process and methods manuals for transparency of decision making, publication of summary reports that inform final recommendations, and multi-representative stakeholder involvement ensuring inclusiveness and scrutiny of decision making.

The resistance from clinicians and other key stakeholders who may not agree with the recommendations made by the MTAB, particularly when recommendations are at odds with existing clinical practice, represents another challenge. The MTAB should be prepared to embrace such challenges by ensuring the transparency and evidence-based nature of the decision-making processes it employs. In this way it can celebrate rather than fear the rich democratic institutions of the country and the legitimacy that they will ultimately confer on the recommendations emerging from the HTA process.

Finally, the vast and complex Indian health system presents a uniquely intimidating challenge in itself. Health 
care in India is largely financed through out-of-pocket payments [15] and provided, for the most part, by an increasingly strong and minimally regulated private sector. In addition to this, it is important to note that state government spending comprises approximately $66 \%$ of total public sector spending [15]. The MTAB, however, has been conceived as a body that will predominantly guide the national MoHFW, i.e. guide public sector health financing at the national level. In such a context, in order to be truly effective in helping India to achieve UHC, it will be crucial for the MTAB to understand how best to have influence at both the national and state level, and engage with both public and private sector health care providers. Creation of the MTAB would provide more impetus to state-specific attempts at assessing value for money in the health sector [16].

The creation of the MTAB is a landmark development towards evidence-based health policy making in India and represents an essential step towards India's path to UHC. In order to achieve UHC, several difficult resource allocation decisions must be made. Using the evidence-based and transparent HTA processes advocated by the MTAB, these decisions can be made in a manner that ensures efficient and equitable health care provision.

\section{Compliance with Ethical Standards}

Funding No funding was received for this paper.

Conflict of interest Shankar Prinja, Laura E. Downey, Vijay K. Gauba and Soumya Swaminathan declare no conflict of interest.

Open Access This article is distributed under the terms of the Creative Commons Attribution-NonCommercial 4.0 International License (http://creativecommons.org/licenses/by-nc/4.0/), which permits any noncommercial use, distribution, and reproduction in any medium, provided you give appropriate credit to the original author(s) and the source, provide a link to the Creative Commons license, and indicate if changes were made.

\section{References}

1. Commission Planning. Twelfth five year plan 2012-17. New Delhi: Government of India; 2012.
2. Government of India. National Health Policy-2017. Ministry of Health and Family Welfare. Government of India. 2017. http:// www.mohfw.nic.in/showfile.php?lid=4275. Accessed $24 \mathrm{Apr}$ 2017.

3. Rashtriya Swasthya Bima Yojana. RSBY guidelines. 2008. http:// www.rsby.gov.in/Documents.aspx?ID=1. Accessed 24 Apr 2017.

4. GoI. Union Budget 2016. Ministry of Finance. Government of India. 2016. http://www.indiabudget.nic.in/. Accessed 24 Apr 2017.

5. Press Information Bureau Government of India. A new health protection scheme to provide health cover up to Rs. 1 lakh per family announced. Ministry of Finance. 2016. http://pib.nic.in/ newsite/PrintRelease.aspx?relid=136989. Accessed 24 Apr 2017.

6. NITI Aayog. Report of the Sub-Group of Chief Ministers on Rationalisation of Centrally Sponsored Schemes. 2015.

7. GoI. Fourteenth Finance Commission Report. Ministry of Finance. Government of India. 2013. http://finmin.nic.in/ 14fincomm/14fcreng.pdf. Accessed 24 Apr 2017.

8. Glassman A, Chalkidou K. Priority-setting in health building institutions for smarter public spending. Center for Global Development's Priority-Setting Institutions for Global Health Working Group, 2012.

9. Press Information Bureau Government of India. Medical Technology Assessment Board. Ministry of Health and Family Welfare. 2017. http://pib.nic.in/newsite/mbErel.aspx?relid=157976. Accessed 24 Apr 2017.

10. Department of Health Research. MTAB notification. Personal communication to Shankar Prinja (shankarprinja@gmail.com) 2017 Apr 3. Accessed on 24 Apr 2017.

11. Prinja S, Chauhan AS, Angell B, Gupta I, Jan S. A systematic review of the state of economic evaluation for health care in India. Appl Health Econ Health Policy. 2015;13(6):595-613.

12. Economic evaluation for HTA. School of Public Health, Post Graduate Institute of Medical Education and Research. http:// www.healtheconomics.pgisph.in/. Accessed 24 Apr 2017.

13. Prinja S, Jeet G, Verma R, Kumar D, Bahuguna P, Kaur M, Kumar R. Economic analysis of delivering primary health care services through community health workers in 3 North Indian states. PLoS One. 2014;9(3):e91781.

14. Prinja S, Gupta A, Verma R, Bahuguna P, Kumar D, Kaur M, Kumar R. Cost of delivering health care services in public sector primary and community health centres in North India. PLoS One. 2016;11(8):e0160986.

15. MOHFW. National health accounts: estimates for India 2013-14. National Health Accounts Technical Secretariat (NHATS). National Health Systems Resource Centre (NHSRC). Ministry of Health and Family Welfare (MoHFW). Government of India. New Delhi, 2016.

16. Prinja S, Bahuguna P, Faujdar DS, Jyani G, Srinivasan R, Ghoshal S, Suri V, Singh MP, Kumar R. Cost effectiveness of HPV vaccination for adolescent girls in Punjab State: implications for India's UIP program. Cancer. 2017. doi:10.1002/cncr. 30734. 